\title{
PENERAPAN DATA MINING MENGGUNAKAN ALGORITMA K-MEANS UNTUK MENGETAHUI MINAT CUSTOMER DI TOKO HIJAB
}

\author{
Yulianti'; Dwi Yuni Utami²; Noer Hikmah³; Fuad Nur Hasan ${ }^{4}$ \\ ${ }^{1}$ Program Pascasarjana Magister Ilmu Komputer STMIK Nusa Mandiri \\ www.nusamandiri.ac.id \\ yuleeseunggi@gmail.com \\ ${ }^{2}$ Teknik Komputer \\ Universitas Bina Sarana Informatika \\ www.bsi.ac.id \\ dwi.dyu@bsi.ac.id \\ ${ }^{3}$ Sistem Informasi \\ Universitas Bina Sarana Informatika \\ www.bsi.ac.id \\ noer.nhh@bsi.ac.id \\ 4IImu Komputer \\ Universitas Bina Sarana Informatika \\ www.bsi.ac.id \\ fuad.fnu@bsi.ac.id
}

\begin{abstract}
Hijab is not a foreign thing for the population in Indonesia, because most of the population of Indonesia is Muslim. Today, many business people, especially hijab sellers, provide a variety of brands and models in the hijab they sell. Therefore sellers are required to be able to think intelligently in making a sales strategy that will certainly be useful to know clearly which products are most in demand by customers, and also to increase sales in their stores. Then there needs to be an alternative that can realize the recording of sales transaction data more quickly and structured. In this study the authors applied the $k$-means algorithm to determine customer interest in the products they sell. In the calculation that has been done by using two parameters, namely the transaction and the number of sales and passing three iterations with the results of iterations one gets a ratio of 0.374324132 , the iteration two gets the ratio 0.543018325 , and the iteration three gets the same ratio value as second iteration. So it can be concluded that the hijab that is most desirable by the customers is the hijab with the brand Rabbani, Elzatta, and Zoya, the low-interest hijab branded by Dian Pelangi, Kami Idea, and Meccanism. And the hijab with those who are not high and also not low is the hijab under the brand Ria Miranda, Jenahara, Shasmira, and Shafira.
\end{abstract}

Keywords: Hijab, Customer Interest, K-Means Method
Abstrak-Hijab bukanlah hal yang asing bagi penduduk di Indonesia, karna sebagian besar dari penduduk Indonesia beragama islam. Saat ini banyak para pelaku bisnis terutama penjual hijab yang menyediakan berbagai macam brand dan model pada hijab yang mereka jual. Oleh sebab itu para penjual di tuntut untuk dapat berfikir cerdas dalam membuat strategi penjualan yang pastinya akan berguna untuk mengetahui dengan jelas produk mana yang paling diminati oleh para customer, dan juga untuk meningkatkan penjualan pada toko mereka. Maka perlu adanya suatu alternatif yang dapat mewujudkan pencatatan data transaksi penjualan dengan lebih cepat dan terstruktur. Dalam penelitian ini penulis menerapkan algoritma k-means untuk mengetahui minat customer terhadap produk yang mereka jual. Pada perhitungan yang telah dilakukan dengan menggunakan dua buah parameter yaitu transaksi dan jumlah penjualan dan melewati tiga kali melakukan iterasi dengan hasil iterasi satu mendapatkan nilai rasio sebesar 0,374324132, iterasi dua mendapatkan rasio 0,543018325, dan iterasi tiga mendapatkan nilai rasio yang sama dengan iterasi kedua. Maka dapat disimpulkan bahwa hijab yang paing diminati oleh para customer adalah hijab dengan brand Rabbani, Elzatta, dan Zoya, hijab yang peminatnya rendah dengan brand Dian Pelangi, Kami Idea, dan Meccanism. Dan hijab dengan peminat yang tidak 
tinggi dan juga tidak rendah adalah hijab dengan brand Ria Miranda, Jenahara, Shasmira, dan Shafira.

Kata Kunci: Hijab, Minat Customer, Metode KMeans

\section{PENDAHULUAN}

Indonesia yang secara demografis merupakan negara berpenduduk muslim terbesar di dunia (Hafidhuddin, 2011). Akan hal tersebut terlihat salah satu bisnis yang saat ini berkembang pesat adalah hijab, fakta bahwa sudah pasti kebutuhan para muslimah di Indonesia akan hijab sangatlah besar. Fenomena perkembangan muslim fashion di Indonesia dapat di lihat pada kehidupan sehari-hari di mana trand penggunaan hijab dikalangan muslimah semakin meningkat (Istiani, 2015).

Sebagai salah satu negara berkembang yang juga mendominasi pertumbuhan penduduk dunia, Indonesia memiliki jumlah penduduk 237 juta jiwa, dengan perbandingan laki-laki dan perempuan 1000 : 986 jiwa. Saat ini Indonesia menempati posisi ke empat, setelah China, India dan Amerika Serikat sebagai Negara dengan jumlah penduduk terbanyak. Rata-rata penduduk Indonesia di dominasi oleh usia remaja dan anakanak, menurut data dari BPS usia remaja pria mencapai $66,5 \%$ dan wanita mencapai $27,3 \%$. Hal tersebut menjadi salah satu kekuatan penting dalam perekonomian Indonesia karena penduduk usia muda dan anak-anak merupakan target pasar untuk para pelaku usaha (Sari, 2017).

Toko Hijab adalah salah satu badan usaha yang bergerak diritel yang melayani customer dalam penjualan hijab. Dalam penjualan hal yang paling penting adalah pengadaan stok tetapi pada toko hijab biasanya untuk pengadaan stok barang masih menggunakan perkiraan saja (Sutanto, Setiawan, \& Setiabudi, 2017), hal ini dikarenakan pemilik tidak ingin terjadi kekurangan stok produk hijab tertentu apabila terjadi permintaan customer dalam jumlah yang besar, maka pemilik mengambil langkah yaitu melakukan pemesanan produk hijab tertentu lebih besar dari sebelumnya. Hal ini dapat mengatasi kekurangan stok produk tertentu dan Toko Hijab tidak perlu melakukan pemesanan berulang-ulang ke distributor. Sehingga kesulitan yang dialami yaitu seringnya toko mengalami kekurangan stok (Dahlan, Jauharul, \& Utsalina, 2017) produk hijab yang laku karena penjualannya tinggi dan menumpuknya produk yang tidak laku digudang karena penjualannya rendah (Metisen \& Sari, 2015).

Untuk mendapatkan pengetahuan tersebut maka perlu adanya suatu proses pengolahan data historis transaksi besar yaitu teknik data mining. yang didapat dengan mempelajari teori-teori literatur dan jurnal-jurnal yang berhubungan dengan objek kajian baik secara online maupun offline dan manganalisa data yang ada dengan melakukan perhitungan manual di excel yang nantinya untuk dijadikan bahan rujukan pemilik dalam memanajemen stok barang dan untuk mengelompokkan produk yang harus memiliki jumlah stok banyak karna sangat diminati, jumlah stok sedang karna diminati dan jumlah stok sedikit karna kurang diminati dari beragam produk hijab yang ada. Dan diharapkan penelitian ini dapat menjadi strategi bisnis pemilik dalam mengambil keputusan yang baik bagi bisnisnya untuk jangka waktu yang panjang dimasa depan.

K-Means merupakan salah satu metode data clustering non hierarki yang berusaha mempartisi data yang ada ke dalam bentuk satu atau lebih cluster atau kelompok sehingga data yang memiliki karakteristik yang sama dikelompokkan ke dalam satu cluster yang sama dan data yang mempunyai karakteristik yang berbeda dikelompokkan ke dalam kelompok yang lainnya (Metisen \& Sari, 2015).

Sedangkan pada penelitian lain metode kmeans digunakan untuk sistem pengambilan keputusan yang dapat digunakan untuk membantu pengelompokkan kemampuan siswa pada mata pelajaran Ujian Nasional. Tujuan dari dibuatnya penelitian ini adalah untuk mengetahui minat customer pada produk hijab yang ditentukan berdasarkan data transaksi dan penjualan dengan metode k-means (Agustin, Fitria, \& S, 2015).

\section{BAHAN DAN METODE}

Dalam penelitian ini peneliti manggunakan data mining dengan algoritma pengelompokkan $\mathrm{k}$ means, dimana data minat customer terhadap hijab pada Toko Hijab untuk membantu memanajemen stok produk hijab terbagi menjadi tiga kelompok yaitu hijab yang kurang diminati (C1) yaitu brand hijab kami idea, dian pelangi, dan meccanism, hijab yang diminati (C2) yaitu Shasmira, Ria Miranda, Jenahara, dan Shafira, dan hijab yang sangat diminati (C3) yaitu brand hijab Rabbani, Zoya, dan Elzatta .

Tujuannya agar objek yang tergabung dalam kelompok merupakan ukuran kedekatan atau hubungan satu sama lain berbeda dengan kelompok yang lainnya. Jarak merupakan ukuran yang digunakan kemiripan dari suatu objek. Pada proses pemilihan ini, dapat dipilih salah satu dari beberapa jarak yang biasa digunakan. Salah satunya adalah jarak Euclidean atau akar dari jumlah kuadrat perbedaan didalam nilai untuk setiap variabel. 
Algoritma pengelompokkan k-means dapat dilakukan dengan cara sebagai berikut:

1. Pilih jumlah cluster $\mathrm{k}$.

2. Inisialisasi $\mathrm{k}$ pusat cluster ini bisa dilakukan dengan berbagai cara. Namun yang paling sering dilakukan adalah dengan cara random. Pusat-pusat cluster diberiduberi nilai awal dengan angka-angka random,

3. Alokasikan semua data ke centroid terdekat dengan metric jarak yang sudah ditetapkan. Untuk menghitung jarak semua data ke setiap tiitk pusat cluster dapat menggunakan beberapa teori jarak seperti Euclidean, Squared Euclidean Distance,Chebychev dan Manhattan atau City block.

4. Hitung kembali centroid $\mathrm{C}$ berdasarkan data yang mengikuti cluster masing-masing

5. Tugaskan lagi setiap objek memakai pusat cluster yang baru. Jika pusat cluster tidak berubah lagi maka proses clustering selesai. Atau, kembali ke langkah nomor 3 sampai pusat cluster tidak berubah.

Penelitian ini dilakukan dengan beberapa tahap:

1. Pengumpulan Data

Penulis menggunakan data yang diperoleh dari hasil observasi berdasarkan kisaran rata-rata brand hijab yang paling diminati oleh muslimah di Indonesia terutama yang terlihat langsung disekitaran lingkungan masyarakat. Data diambil dari jurnalbumi kemudian di kumpulkan berdasarkan data-data brand hijab. Adapun data hijab yang terdapat pada situs tersebut dapat dilihat dibawah ini:

Tabel 1. Data Hijab

\begin{tabular}{cl}
\hline No & \multicolumn{1}{c}{ Nama Produk Hijab } \\
\hline 1 & Rabbani \\
\hline 2 & Dian Pelangi \\
\hline 3 & Ria Miranda \\
\hline 4 & Jenahara \\
\hline 5 & Shasmira \\
\hline 6 & Elzatta \\
\hline 7 & Kami Idea \\
\hline 8 & Shafira \\
\hline 10 & Meccanism \\
\hline
\end{tabular}

Sumber: (Rollick, 2017)

2. Pengolahan Data

Data yang telah diperoleh kemudian akan diolah terlebih dahulu untuk dapat diclustering. data yang akan diolah akan menggunakan dua parameter yaitu transaksi dan jumlah penjualan produk hijab. Sehingga pada tahapan ini sudah diperoleh perhitungan nilai yang akan diproses pada tahap clustering. Pada tahap clustering proses partisi sekumpulan objek data dari satu set akan dibagi menjadi beberapa kelas. Hal ini dapat dilakukan dengan menerapkan persamaan dan langkah-langkah mengenai jarak algoritma.

Menurut (Metisen \& Sari, 2015) clustering adalah metode yang digunakan untuk membagi rangkaian data menjadi beberapa group berdasarkan kesamaan-kesamaan yang telah ditentukan sebelumnya. Cluster adalah sekelompok atau sekumpulan objek-objek data yang disimilar terhadap objek-objek yang berbeda cluster. Objek akan dikelompokkan ke satu atau lebih cluster sehingga objek-objek yang berada dalam satu cluster akan memiliki kesamaan yang tinggi antar satu dengan yang lainnya.

3. Analisis Data

Analisis data yang dipakai pada penelitian ini adalah membagi rangkaian data menjadi beberapa grup berdasarkan kesamaankesamaan yang telah ditentukan sebelumnya.

a. Data dalam satu cluster memiliki tingkat kesamaan penjualan yang rendah.

b. Data dalam cluster yang memiliki tingkat kesamaan penjualan yang sedang.

c. Data dalam cluster yang memiliki tingkat kesamaan penjualan yang tinggi.

Berdasarkan analisis tersebut kemudian terbagi menjadi tiga kelompok (cluster) yaitu C1 yang terdiri dari produk tingkat penjualan rendah (Dian Pelangi, Kami Idea, dan Meccanism), C2 yang terdiri dari produk tingkat penjualan sedang (Ria Miranda, Jenahara, Shasmira, dan Shafira), dan sisanya C3 yang terdiri dari produk tingkat penjualan tinggi (Rabbani, Elzatta, dan Zoya).

Proses perhitungan yang telah disebutkan sebelumnya akan dihitung melalui Ms. Excel. Microsoft Office Excel adalah sebuah program aplikasi lembar kerja spreadsheet yang dibuat dan didistribusikan oleh Microsoft Corporation untuk sistem operasi Microsoft Windows dan Mac.OS. Aplikasi ini memiliki fitur kalkulasi dan pembuatan grafik yang, dengan menggunakan strategi marketingMicrosoft yang agresif, menjadikan Microsoft Excel sebagai salah satu program komputer yang populer digunakan di dalam computer mikro hingga saat ini (Sulindawati, 2016).

\section{HASIL DAN PEMBAHASAN}

Dalam melakukan clustering, data yang diperoleh akan dihitung terlebih dahulu berdasarkan parameter yang ada yaitu transaksi dan jumlah penjualan seperti yang ditunjukan pada tabel 1 berikut:

Tabel 2. Pengumpulan Data 


\begin{tabular}{cccc}
\hline No & Nama & \multicolumn{2}{c}{ Parameter } \\
\cline { 3 - 4 } & & Transaksi & $\begin{array}{c}\text { Penjualan } \\
\text { Produk }\end{array}$ \\
\hline 1 & Rabbani & 20 & 38 \\
\hline 2 & Dian Pelangi & 5 & 8 \\
\hline 3 & Ria Miranda & 13 & 15 \\
\hline 4 & Jenahara & 7 & 7 \\
\hline 5 & Shasmira & 9 & 11 \\
\hline 6 & Elzatta & 25 & 30 \\
\hline 7 & Kami Idea & 5 & 7 \\
\hline 8 & Shafira & 8 & 15 \\
\hline 9 & Meccanism & 3 & 9 \\
\hline 10 & Zoya & 17 & 33 \\
\hline
\end{tabular}

Sumber : (Yulianti, Utami, Hikmah, \& Hasan, 2019)

Kemudian data tersebut akan masuk ketahapan clustering dengan menerapkan algoritma k-means untuk mengcluster data kedalam tiga cluster.

\section{A. Centroid Dato}

Dalam penerapan algoritma K-means dihasilkan nilai titik tengah atau centroid dari data yang didapat dengan ketentuan bahwa clusterisasi yang diinginkan adalah 3. Penentuan cluster dibagi atas tiga bagian yaitu cluster dengan tingkat transaksi rendah (C1), cluster dengan tingkat transaksi sedang (C2), dan cluster dengan tingkat transaksi tinggi (C3). Penentuan titik cluster ini dilakukan dengan mengambil nilai tengah untuk cluster dengan tingkat transaksi rendah (C1), transaksi sedang (C2), dan transaksi tinggi (C3). Nilai titik tersebut dapat diketahui pada tabel dua berikut:

Tabel 3. Penentuan Centroid Awal

\begin{tabular}{cc|cc|cc|c}
$\begin{array}{c}\text { Atrib } \\
\text { ut }\end{array}$ & $\begin{array}{c}\text { Cluster } \\
\text { transaksiRen } \\
\text { dah }\end{array}$ & $\begin{array}{c}\text { Cluster } \\
\text { transaksiSed } \\
\text { ang }\end{array}$ & $\begin{array}{c}\text { Cluster } \\
\text { transaksiTi } \\
\text { nggi }\end{array}$ \\
\hline Nilai & 5 & 7 & 9 & 11 & 20 & 38 \\
\hline Sumber : (Yulianti et al, 2019)
\end{tabular}

\section{B. Clustering Data}

Dengan menggunakan centroid tersebut maka dapat dicluster data yang telah didapat menjadi 3 cluster. Proses cluster dengan mengambil jarak terdekat dari setiap data yang diolah. Dari data transaksi dan penjualan pada toko hijab $\mathrm{xxx}$ didapatkan pengelompokan pada iterasi 1 untuk tiga cluster tersebut. Cluster tingkat populasi rendah (C1) yaitu brand hijab kami idea, dian pelangi, dan meccanism, cluster dengan tingkat transaksi dan penjualan sedang (C2) yaitu Shasmira, Ria Miranda, Jenahara, dan Shafira, dan cluster dengan tingkat transaksi dan penjualan tinggi (C3) adalah brand hijab Rabbani, Zoya, dan Elzatta. Proses pengelompokkan data pada iterasi 1 dan clustering data dapat dilihat pada tabel berikut:

Tabel 4. Hasil Perhitungan Iterasi 1

\begin{tabular}{|c|c|c|c|c|c|c|c|}
\hline \multirow[b]{2}{*}{ No } & \multirow[b]{2}{*}{ Nama } & \multicolumn{2}{|l|}{ Parameter } & \multirow[b]{2}{*}{$\mathrm{C} 1$} & \multirow[b]{2}{*}{$\mathrm{C} 2$} & \multirow[b]{2}{*}{ C3 } & \multirow[b]{2}{*}{ MIN } \\
\hline & & Transaksi & $\begin{array}{l}\text { Penjualan } \\
\text { Produk }\end{array}$ & & & & \\
\hline 1 & Rabbani & 20 & 38 & 34,4 & 29,2 & 0 & 0 \\
\hline 2 & Dian Pelangi & 5 & 8 & 1 & 5 & 33,54102 & 1 \\
\hline 3 & Ria Miranda & 13 & 15 & 11,3137085 & 5,656854 & 24,04163 & 5,656854 \\
\hline 4 & Jenahara & 7 & 7 & 2 & 4,472136 & 33,61547 & 2 \\
\hline 5 & Shasmira & 9 & 11 & 5,656854249 & 0 & 29,15476 & 0 \\
\hline 6 & Elzatta & 25 & 30 & 30,47950131 & 24,83948 & 9,433981 & 9,433981 \\
\hline 7 & Kami Idea & 5 & 7 & 0 & 5,656854 & 34,43835 & 0 \\
\hline 8 & Shafira & 8 & 15 & 8,544003745 & 4123106 & 25,94224 & 4,123106 \\
\hline 9 & Meccanism & 3 & 9 & 2,828427125 & 6,324555 & 33,61547 & 2,82842712 \\
\hline 10 & Zoya & 17 & 33 & 28,63564213 & 23,4094 & 5,83095 & 5,830952 \\
\hline
\end{tabular}

Sumber : (Yulianti et al., 2019)

Proses K-means akan terus beriterasi sampai pengelompokkan data sama dengan pengelompokkan data iterasi sebelumnya. Dengan kata lain, proses akan terus melakukan iterasi sampai data pada iterasis terakhir sama dengan iterasi sebelumnya. Pada penelitian ini proses iterasi berhenti pada iterasi ketiga, adapun untuk nilai centroid pada iterasi ketiga dapat dilihat pada tabel dibawah ini:

Tabel 5. Centroid Pada Iterasi Ke-3

\begin{tabular}{|c|c|c|c|}
\hline Atribut & $\begin{array}{c}\text { Cluster } \\
\text { transaksiRendah }\end{array}$ & $\begin{array}{c}\text { Cluster } \\
\text { transaksiSedang }\end{array}$ & $\begin{array}{c}\text { Cluster } \\
\text { transaksiTinggi }\end{array}$ \\
\hline Nilai & $\begin{array}{c}4,333333333 \\
\mid \quad 8\end{array}$ & $9,25 \mid 12$ & $\begin{array}{c}20,67 \\
33,67\end{array}$ \\
\hline
\end{tabular}

Sumber : (Yulianti et al., 2019)
Setelah mendapatkan nilai titik tengah atau centroid, proses sama dilakukan dengan mencari jarak terdekat. Pencarian jarak terpendek pengelompokkan data pada iterasi kelima, dan clustering data untuk mengetahui minat customer dapat dilihat melalui proses iterasi tiga, pada iterasi tiga ditemukan C1 memiliki 3 anggota, C2 memiliki 4 anggota dan C3 memiliki 3 anggota. Pada tabel dibawah ini menjelaskan bahwa keanggotaan cluster diambil dari nilai yang paling terkecil antara C1, C2, dan C3. Berikut adalah tabel iterasi ketiga. 
Tabel 6. Hasil Perhitungan Iterasi Ke-3

\begin{tabular}{lllll}
\hline \multicolumn{1}{c}{ Nama Produk } & \multicolumn{1}{c}{ C1 } & C2 & C3 & Keanggotaan \\
\hline Rabbani & 33,84441526 & 28,13472 & 30,07029 & \\
\hline Dian Pelangi & 0,666666667 & 5,836309 & 20,17975 & C1 \\
\hline Ria Miranda & 11,14051664 & 4,802343 & 29,96479 & C2 \\
\hline Jenahara & 2,848001248 & 5,482928 & 25,49292 & C2 \\
\hline Shasmira & 5,547772326 & 1,030776 & 5,676462 & C3 \\
\hline Elzatta & 30,18461713 & 23,91783 & 30,92823 & C1 \\
\hline Kami Idea & 1,201850425 & 6,562202 & 22,55857 & C2 \\
\hline Shafira & 7,902179727 & 3,25 & 30,34066 & C1 \\
\hline Meccanism & 1,666666667 & 6,932712 & 3,72678 \\
\hline Zoya & 28,02578178 & 22,38443 & & \\
\hline
\end{tabular}

Sumber : (Yulianti et al., 2019)

Untuk mengetahui minat customer dapat dilihat melalui proses iterasi tiga, pada iterasi tiga diketahui C1 memiliki 3 anggota, C2 memiliki 4 anggota dan C3 memiliki 3 anggota. Pada tabel diatas menjelaskan bahwa keanggotaan cluster diambil dari nilai yang paling kecil antara C1, C2, dan C3.

\section{Analisis Hasil}

Hasil dari analisa algoritma K-means diatas dengan tujuan untuk mengetahui minat customer pada brand produk hijab yang terdapat pada toko hijab ini dihasilkan dari data yang telah dihitung dengan Ms excel. Perhitungan dilakukan dengan terlebih dahulu membagi data yang ada kedalam beberapa cluster berdasarkan dari dua parameter yang ada yaitu transaksi dan jumlah penjualan. Proses iterasi akan dihentikan apabila hasil rasio memiliki nilai yang sama dengan rasio sebelumnya. Hasil dari analisa pada penelitian ini terdapat tiga kali melakukan proses iterasi, iterasi satu mendapatkan hasil rasio 0,37432413, iterasi dua mendapatkan hasil rasio 0,54301833, dan iterasi tiga hasil rasionya sama dengan iterasi kedua.

Tabel 7. Hasil Iterasi 1-3

\begin{tabular}{ccccc}
\hline Iterasi & BCV & WCV & Rasio & $\begin{array}{c}\text { Rasio } \\
\text { Sebelumnya }\end{array}$ \\
\hline $\begin{array}{c}\text { Iterasi } \\
1\end{array}$ & 69 & 185 & 0,374324132 & 0 \\
\hline $\begin{array}{c}\text { Iterasi } \\
2\end{array}$ & 61 & 113 & 0,543018325 & 0,374324132 \\
\hline $\begin{array}{c}\text { Iterasi } \\
3\end{array}$ & 61 & 113 & 0,543018325 & 0,543018325 \\
\hline
\end{tabular}

Sumber : (Yulianti et al., 2019)

Adapun untuk hasil lain yang didapat seperti penjelasan dibawah ini:

1. C1 merupakan cluster yang peminatnya paling sedikit, brand hijab yang masuk dalam cluster ini adalah Dian Pelangi, Kami Idea, dan Meccanism.

2. C2 merupakan cluster yang peminatnya tidak sedikit dan tidak juga terlalu banyak yaitu Ria Miranda, Jenahara, Shasmira, dan Shafira.

3. C3 merupakan cluster yang peminatnya paling banyak, brand hijab yang masuk dalam cluster ini adalah Rabbani, Elzatta, dan Zoya.

Tabel 8. Hasil Pengelompokkan

\begin{tabular}{ll}
\hline Nama Produk & Keanggotaan \\
\hline Rabbani & C3 \\
\hline Dian Pelangi & C1 \\
\hline Ria Miranda & C2 \\
\hline Jenahara & C2 \\
\hline Shasmira & C2 \\
\hline Elzatta & C3 \\
\hline Kami Idea & C1 \\
\hline Shafira & C2 \\
\hline Meccanism & C1 \\
\hline Zoya & C3
\end{tabular}

Sumber : (Yulianti et al., 2019)

\section{KESIMPULAN}

Berdasarkan hasil dari analisa dan pengolahan data pada pembahasan diatas, dapat ditarik kesimpulan sebagai berikut:

Untuk mengetahui minat customer pada toko hijab ditentukan berdasarkan data transaksi dan data penjualan. Hasil yang didapatkan menggunakan algotitma K-means bahwa cluster satu adalah brand hijab yang memiliki peminat yang rendah yaitu, Dian Pelangi, Kami Idea, dan Meccanism. Pada cluster tiga memiliki peminat yang paling tinggi terdiri dari Rabbani, Elzatta, dan Zoya. Dan Ria Miranda, Jenahara, Shasmira, dan Shafira masuk dalam cluster dua yang memiliki peminat yang tidak rendah dan juga tidak tinggi atau berada ditengah.

\section{REFERENSI}

Agustin, F. E. M., Fitria, A., \& S, A. H. (2015). IMPLEMENTASI ALGORITMA K-MEANS UNTUK MENENTUKAN KELOMPOK PENGAYAAN MATERI MATA PELAJARAN UJIAN NASIONAL (STUDI KASUS: SMP NEGERI 101 JAKARTA). Jurnal Teknik Informatika, 8(1), 73-78. 
Dahlan, M., Jauharul, M., \& Utsalina, D. S. (2017). SISTEM INFORMASI PERAMALAN PENJUALAN KRIPIK PISANG MENGGUNAKAN METODE DOUBLE EXPONENTIAL SMOOTHING BERBASIS WEB PADA TOKO TIGA PUTRA DI LUMAJANG. Seminar Nasional Sistem Informasi, (14 September), 676-686.

Hafidhuddin, D. (2011). Peran Strategis Organisasi Zakat Dalam Menguatkan Zakat Di Dunia (The Strategic Role of Zakat Organization in Strengthening Zakah in the World). Jurnal Ekonomi Islam Al-Infaq, 2(1, Maret 2011), 14.

Istiani, A. N. (2015). Konstruksi Makna Hijab Fashion Bagi Moslem Fashion Blogger. Jurnal Kajian Komunikasi, 3(1), 48-55. https://doi.org/10.24198/jkk.vol3n1.6

Metisen, B. M., \& Sari, H. L. (2015). Analisis Clustering Menggunakan Metode K-Means Dalam Pengelompokkan Penjualan Produk Pada Swalayan Fadhila. Jurnal Media Infotama, 11(2, September 2015), 110-118.
Rollick, A. (2017). 10 Merek Jilbab Ternama di Indonesia. Retrieved February 3, 2019, from https://jurnalbumi.com/top/merek-jilbabternama-di-indonesia/

Sari, A. M. (2017). APLIKASI SITUS WEB PENJUALAN HIJAB ONLINE. Paradigma Jurnal Komputer Dan Informatika, 19(2), 113117. https://doi.org/https://doi.org/10.31294/p. v19i2.2290

Sulindawati, N. L. G. E. (2016). Pengembangan Model Pembelajaran. Seminar Nasional Riset Inovatif (Senari), 323-334.

Sutanto, P., Setiawan, A., \& Setiabudi, D. H. (2017). Perancangan Sistem Forecasting di Perusahaan Kayu UD . 3G dengan Metode ARIMA. Jurnal Infra, 05(01), 325-330.

Yulianti, Y., Utami, D. Y., Hikmah, N., \& Hasan, F. N. (2019). PENERAPAN DATA MINING MENGGUNAKAN ALGORITMA K-MEANS UNTUK MENGETAHUI MINAT CUSTOMER DI TOKO HIJAB. STMIK Nusa Mandiri. 